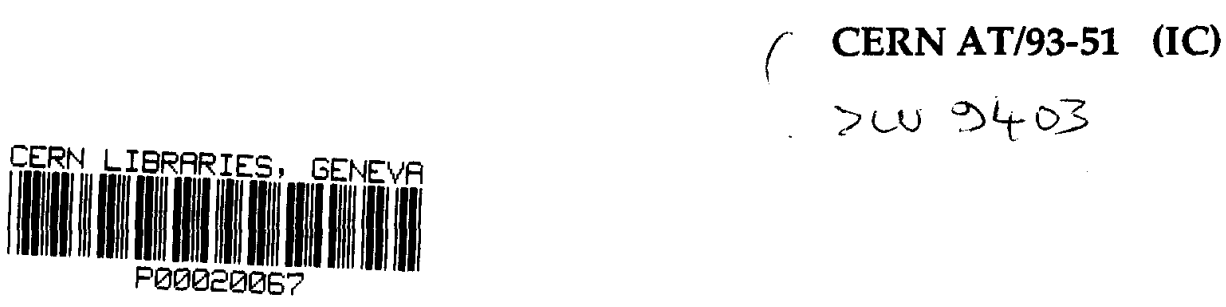

Specification, Installation and Commissioning of a Large Industrial Control System for the LEP200 Cryogenics

H.K. Kuhn, A.C. Juillerat, M. Rabany and J.C. Wollès

ICALEPCS'93 - International Conference on

Accelerator and Large Experimental Physics Control Systems,

Berlin, Germany, October 18-22, 1993 


\title{
Specification, Installation and Commissioning of a Large Industrial Control System for the LEP200 Cryogenics
}

\author{
H.K.Kuhn, A.C.Juillerat, M.Rabany, J.C.Wollès \\ CERN, Group AT-IC, 1211-Geneva-23, Switzerland
}

CERN is upgrading the LEP $\mathrm{e}^{+}-\mathrm{e}^{-}$collider for energies above the $\mathrm{Z}_{0}$ particle by installing super-conducting cavities. The cryogenic system attached to these cavities is controlled by a distributed, industrial control system, having been the object of a tender. The issues relate to the software specification, the management of the contract, the installation and the gradual commissioning of the system. The experience with a fully farmed out solution is reported.

\section{Scope of the Cryogenics Hardware}

Since early 1990 CERN pursues the project LEP-200 Upgrade [1]. To achieve this doubling of LEP's present energy, a total of 192 superconducting accelerating cavities must be installed in the four even numbered points at LEP, together with four cryogenic plants [2], one per site, with an initial cooling power of $12 \mathrm{~kW}$ at $4.5^{\circ} \mathrm{K}$, to be upgraded to $18 \mathrm{~kW}$ once the future Large Hadron Collider LHC gets constructed. These cryogenic plants had to be split into five distinctive segments: The compressor part, housed in one building, the site control in an adjacent, noise insulated building and in another surface building the "Upper Coldbox" for the $300^{\circ} \mathrm{K}$ to $20^{\circ} \mathrm{K}$ He cool-down range. Down in the tunnel, from $40 \mathrm{~m}$ to $100 \mathrm{~m}$ below the surface, one finds the "Lower Coldbox" for the $20^{\circ} \mathrm{K}$ to $4.5^{\circ} \mathrm{K}$ range, and upstream and downstream of the local center the load in the form of the superconducting cavities. In addition to these four plants two smaller ones of $6 \mathrm{~kW}$ each were ordered, to precede the delivery of the large ones. The contracts for this hardware, together with the delivery schedules for this equipment worth $52 \mathrm{MSFr}$ were adjudicated in December 1990. Earlier, it had been decided to place an entirely separate order for the related Process Control equipment.

For reasons specific to the CERN, the cryogenic equipment was ordered from two different companies, Sulzer/Linde (CH/D) and Air Liquide (F). The delivery of the $6 \mathrm{~kW}$ units started early June 1991, one each of the $12 \mathrm{~kW}$ plants was to arrive mid-1992 and the other two in 1993, always more or less in parallel. None of the essentially four types of helium liquefiers had ever been built before in these sizes.

Key points to be retained here are:

- Cryogenics hardware ordered independently of Process Control equipment

- Hardware delivery planned without consideration of Controls needs

- Controls people had no influence on cryogenics contracts

\section{The Process Controls Specification Process}

When the Controls specifications wer established, hardware requirements for Input/Output controls could at best be scaled upwards from existing smaller $1.2 \mathrm{~kW}$ plants. Prior to this the Cryo people had gained some experience with one industrial make and its software. They had written all their programs by themselves, after a three-week training course on the SW language and with the ongoing assistance of an industry instructor. A group composed of some of these people plus experts on communications and others involved with the project in general finally produced a "Cahier des charges pour Système de Contrôle de la Cryogénie du LEP200" [3].

This document contained the usual electrical and other specifications regarding $1 / O$ channels in a Process Control System, furthermore the physical layout of the Cryogenic installations plus a multitude of other definitions generally found in such papers. Noteworthy is an attempt to define what the authors called a "PU =Process Unit". In there they tried to quantify the Software requirements of one segment of the described cryogenic plant. In terms of capacity in the Process Control System, a PU was defined as a number of measuring and control channels, and a volume of user programs which however did not include the imagery. In an addendum they gave an estimated number of software and hardware constituents, in terms of ORs, ANDs, PIDs etc, and analog/digital I/Os etc. There were no motor lists, $\mathrm{P}+\mathrm{I}$ diagrams, process descriptions nor signal flow diagrams, nor any other precise information available on the future cryogenic plants. One tried to establish a scope for the amount of software to be written without knowing what make and what language finally would be chosen. The revised version of this document [3] then became the "Technical Specification" for the tender IT-1912/LP2/AT of October 1990, Process Control System for LEP200 Cryogenics. Adjudication to the low bidder, AseaBrownBoveri ABB Switzerland, took place end of March 1991. The contract called for 4.5 MSFr to be spent on controls hardware on one hand, and 3.1 MSFr on Software on the other hand. As deliveries of the cryogenic plants would come due, the necessary controls ware would be called up. This would allow to 
profit from possible developments in the product list of the supplier ABB.

By the time negotiations for deliveries could start with ABB, it was April 1991. The urgently required delivery of the first controls hardware was only three months away, slated for June 1991.

Key points to be retained here are:

- Very flexible Hardware delivery conditions

- Controls experts unable to specify properly the plant Software due to lack of specific information

- Bidders faced with detailed Software specifications not really representing what was to come

- Decision making process for Software started much too late

\section{The Initial Phase of the Contract}

The author of this report was put in charge of the contract by early April 1991. During the next few months, meetings were held almost weekly between the representatives of the CERN Industrial Controls group (IC), the Cryogenics group (CR) and $A B B$ Process Automation. Very soon they were almost exclusively devoted to software matters. The Process controls hardware would pose virtually no problems: 10 to 12 weeks after an order was placed, the process control units would be delivered and started up. With the software however the situation soon became critical:

Both the CERN and $A B B$ had put new people in charge of the project. The familiarization time for them was too short, therefore they had to rely much on advice of experts, of which there were essentially only two at that time, one on each side. Whereas the bid was based on a plain design of the software, the two experts decided to opt for the modern trend of the object oriented software, with some of the objects being compressors, turbines, gauges and valves. This choice was also motivated by the inital lack of overall plant specifications, facilitating this way the putting into operation of subsystems. Another goal was to standardize these objects throughout the seven geographically dispersed plants and thus save resources and time and get a uniform software. This was accepted by both project leaders, as each sought that the other one knew exactly what the consequences would be. Both considered the other one as the competent Software expert. As a result of this switch in philosophy it became soon evident that memory in the MasterPieces $\otimes$ would be insufficient. An upgrading in size was implemented. By the time the first cryogenic plant was operational, memory space again run out: This time it was due to trending. As the plant was rather a prototype, many points had to be monitored over a great length of time to fine-tune it. This time a costly basic change for the 30-odd MP units became necessary. The issue was settled, the two partners accepting each part of the responsibility for the overrun. Another omission dating back to the earlier cryogenic plant specifications became now evident: The failure to stipulate in the contracts the suppliers responsibility to furnish, at an early stage, their logic, electrical and plant diagrams. As these documents became available only with the on-site delivery of the hardware, the hoped for sequential installation turned into a parallel one. Thus the software people became hopelessly overburdened. Another unexpected obstacle, but obvious in hindsight, was the slow reaction of the contractor to our rapidly increasing demands on his manpower: We on our side received and put into service two considerably differing plants in parallel and realized that there was not one specific object, but always two, one for Linde, one for AL. ABB on their side had initially not enough people familiar with the notion "Object" and had to train them on the job. Commercial considerations and contractual obligations to other customers prevented them from immediately reassigning manpower. It did not help either that one cryo company supplied their logic in one language, the other one in another. As some of the logic had to be adapted on the plants themselves with the assistance of the respective company's cryogenic engineers, and this concurrently for the two plants, there were often suddenly two versions of basically identical programs. Once CERN's hardware managers became more familiar with the problems, and more time was available, efforts to prevent such dualisms were made and the development of new software distributed between the two types of equipment.

Key points to be retained here are:

- Preparation period for (new) project managers too short

- Managers should be able to spend time in the other company, to understand fully product and counterpart

- Acceptance of strategic decisions under delivery schedule pressure without sufficient evaluation of the consequences

- Plant-, electrical and logical diagrams must be available at the earliest time possible to the Software provider

- Non-standard, differing logical representations by different companies of the plant automatisms (Grafcet, DIN-40719/IEC-848 ?) to be avoided

- Underestimation of, false economies on critical parts in Process Control units (memory, I/O, other) leads to system limitations, possibly renegotiations of contract

\section{The Main Phase of Contract}

As pointed out earlier, the seven plants are spread across the CERN site, an area of about $100 \mathrm{~km}^{2}$. The four LEP-200 plants were to be controlled from one centrally located control room. ABB proposed to use a 
special version of its MasterBus system, said to be in an advanced stage of development and operational in North Sea installations. A first test seemed to be successful, but only a point-to-point connection could be established. Considerable difficulties arose when subsequently more than one site became connected to the central control room. About 18 months after the first tests a satisfying performance was obtained, but not without a considerable effort of in-house manpower. Some other problems became manifest, a color printer supplied by the contractor turned out to be too slow for the extended start-up and testing periods. A replacement model would give satisfaction, but showed up another flaw in the software. The contractor proposed to split the costs of its rectification, but financial constraints forced us to abandon this item and to live with it. To a lesser extent we experienced with the 12 $\mathrm{kW}$ installations once more similar problems as with the $6 \mathrm{~kW}$ ones: Software is, for the hardware supplier, of secondary importance, thus leading almost inevitably to tight scheduling. No such experiences were made with the process equipment, here all deliveries were on time and properly installed on-site well ahead of the required dates. Also, only one or two instances were registered where the hardware would exhibit defects.

Lately $A B B$ and $C E R N$ have begun to exchange electronically the software between the two sites. The first tests proved to be rather time consuming, again to nobody's surprise : this case was nowhere foreseen in the specifications. Once the type of application and its version was agreed, it proved to be a great simplification of the procedures between the two parties. The Master@ system in question offers, in our configuration, to $\mathrm{ABB}$ the possibility to directly intervene from their offices in case of software problems. This certainly saves costs to both partners and reduces intervention time to appreciably lower amounts. Thus a software upgrade in our Super-View ${ }^{\circledR}$ was executed by ABB engineers out of Luleå / Sweden during a CERN holiday.

Key points to be retained here are:

- $\mathbf{a}$ or $\mathbf{b}$ versions of proposed equipments will most likely pose problems

- Contractor decides what priorities he gives to solving a peculiar customer problem

- Limited system flexibility must be accepted, leads on the other hand to reduced numbers of differing modules (four different $1 / O$ modules only in our case)

- Process control hardware is delivered on time and in operational state, very few defects show on start-up of the basic systems

- Electronic data exchange must be foreseen

- Application, format and versions of file transfers should be agreed upon early

\section{Conclusions}

This contract was a first of this size for CERN in the field of Industrial Process Control Equipment where Industry was to furnish an essentially turn-key ready control system. The boundary conditions made it difficult, at least for the onset, to achieve this aim completely. The contract was not treated as an integral part of the overall project, and thus, as enumerated above, a lot of unfavorable conditions were created. This however must be considered as part of the learning process as it is CERN's future way. A policy of reduction of long-term staff is currently called for by the governing Council, and this can be achieved only by involving industry as much as possible. The cooperation with one of the leaders in the Process Automation field has shown that even when the reciprocal interests are not always identical for the two partners, a fruitful and successful cooperation can result. And finally, it must be said that the OBject Oriented Approach/Design was a good choice after all, allowing us now to consolidate the project without rewriting everything.

$A B B$ has come to appreciate the potential a state-of-the-art institution like the CERN may offer them in terms of Technology transfer. CERN's requirements are often so special that they become a demanding test-bed for industrial equipments. It is then only logic that after an initial period of getting to know each other, $A B B$ has now offered us an active participation in their development of new hardware and software in the field of industrial process controls. This way the CERN responsibles will not only manage, but can become active again in a limited way in the development field, and can benefit industry from their knowledge acquired during their professional careers at a leading institution like the CERN.

Key points to be retained here are:

- Costs of controls ware as furnished by Industry amounts to about $10 \%$ of overall Cryogenics hardware outlays

- Both sides, Industry and Scientific Institution, benefit from such a cooperation

\section{References}

[1] C.Wyss "The LEP Energy Upgrade Project", Proc. Part. Acc. Conf., San Francisco, May 1991.

[2] M.Barranco-Luque et al., The Refrigeration System for the LEP Upgrade", XIIIth International Cryogenic Engineering Conference, Beijing, April 1990

[3] Cahier des charges pour Système de Contrôle de la Cryogénie du LEP200, CERN/AT-CR/90, 25 Septembre 1990 
